\title{
Thallium isotopic composition of Earth's earliest continental crust
}

\author{
MATHIAS SCHANNOR ${ }^{* 1}$, HEYE FREYMUTH ${ }^{1}$, JESSE \\ REIMINK $^{2}$, HUGO MOREIRA ${ }^{3}$, MARK REHKÄMPER ${ }^{4}$, HELEN \\ M. WILLIAMS ${ }^{1}$
}

${ }^{1}$ Department of Earth Sciences, University of Cambridge, UK (*correspondence: mss77@cam.ac.uk; hf325@cam.ac.uk, hmw20@cam.ac.uk)

${ }^{2}$ Department of Geosciences, Pennsylvania State University, USA (jreimink@psu.edu)

${ }^{3}$ School of Earth and Environmental Sciences, University of Portsmouth, UK (hugo.moreira@port.ac.uk)

${ }^{4}$ Department of Earth Science and Engineering, Imperial

College London, UK (markrehk@imperial.ac.uk)

The growth and recycling of continental crust have influenced the chemical and thermal modification of the Earth's mantle, hydrosphere, atmosphere and biosphere for more than 4 billion years. However, the nature of the source materials that formed the Earth's early continental crust, as well as the timing and mechanisms of its formation remain controversial. The majority of Archean terranes are comprised of tonalite-trondhjemite-granodiorites (TTGs), rocks that are considered to represent early-formed continental crust. The two prevailing tectonic models for the formation of Archean TTGs, and thus early continental crust, are (i) vertical subduction and partial melting of the downgoing oceanic slab, (ii) partial melting at the base of plumegenerated oceanic plateaux $[1,2]$.

Non-traditional stable isotopes have increasingly been exploited for their potential to isolate specific geological processes and thus constitute ideal tools to address early continental crust formation. For example, the thallium stable isotope system has been successfully employed to identify distinct components in modern subduction zone settings [3], in particular hydrothermally altered and hydrated oceanic crust. To illustrate this point, $\mathrm{Tl}$ isotope data for TTGs from the Paleoproterozoic Mineiro belt in Brazil show significant variation $\left(\varepsilon^{205} \mathrm{Tl} \sim-5\right.$ to +2$)$, that is consistent with the mixing of mantle melts and subduction zone components (altered oceanic crust and sediments). Here we extend our study of $\mathrm{Tl}$ isotopes in TTGs to the Acasta Gneiss Complex, which contains the oldest known terrestrial rocks with igneous crystallization ages ranging from 4.03 to $3.40 \mathrm{Gyr}$ [4]. We use this data to identify the specific geodynamic setting(s) that formed the Earth's early continental crust.

[1] Foley et al. (2002) Nature 417, 637-740. [2] Zegers \& Van Keken (2001) Geology 29, 1083-1086. [3] Nielsen et al. (2017) Rev Mineral Geochem 82, 759-798. [4] Bowring et al. (1989) Geology 17, 971975. 